\title{
The role of computed tomography in predicting peritoneal carcinomatosis and upfront surgery outcome in advanced ovarian cancer
}

Mihaela Asp ( $\square$ mihaela.asp@med.lu.se)

Skane University Hospital https://orcid.org/0000-0002-2130-5132

\section{Susanne Malander}

Lund University: Lunds Universitet

\section{NilsOlof Wallengren}

Lund University: Lunds Universitet

\section{Sonja Pudaric}

Lund University: Lunds Universitet

Johan Bengtsson

Lund University: Lunds Universitet

\section{Hanna Sartor}

Lund University: Lunds Universitet

\section{Päivi Kannisto}

Lund University: Lunds Universitet

\section{Research}

Keywords: ovarian cancer, peritoneal cancer index, cytoreductive surgery.

Posted Date: November 13th, 2020

DOl: https://doi.org/10.21203/rs.3.rs-106455/v1

License: (9) (i) This work is licensed under a Creative Commons Attribution 4.0 International License. Read Full License 


\section{Abstract}

Background Epithelial ovarian cancer is usually diagnosed at advanced stages. To choose the best therapeutic approach, an accurate assessment of the tumor spread is crucial. This study aimed to determine whether numeric scoring, the amount of ascites, and the presence of cardiophrenic nodes (CPLNs) visualized by computed tomography (CT), can predict the tumor extent and improve the outcome of AOC upfront surgery.

Methods This single center retrospective analysis of 194 patients diagnosed with AOC included 119 patients treated with upfront surgery at the Skåne University Hospital, Lund, Sweden, from January 2016 to December 2018.

CT based peritoneal cancer index (PCl) scores, enlarged cardiophrenic lymph nodes (CPLNs), and the amount of ascites were correlated to the surgical PCI (S-PCl) and the completeness of the cytoreductive surgery.

The patients were grouped according to the residual disease (RD) and the overall survival (OS) rates for the three groups were determined using Kaplan-Meier curves. Linear regression and the interclass correlation (ICC) analyses were used to determine the relationship between CT-PCI and S-PCI.

Results The survival rate was significantly higher in patients with no macroscopic residual disease compared those with residual disease $<10 \mathrm{~mm}(p<0.03)$ or residual disease $\geq 10 \mathrm{~mm}(p<0.005)$.

S-PCl and large ascites volumes were correlated with the risk of suboptimal residual disease (for ascites > $1000 \mathrm{ml}$, OR 5.5626 (1.665-19.007) p<0.019; for S-PCl, OR 1.24 (1.141-1.348), $\mathrm{p}<0.001)$. CT-PCl, CA-125 level and CPLN were not predictive of the cytoreductive surgery results in the adjusted data to days from CT to operation and for ascites. CT-PCl correlated well to S-PCI ((95\%) Cl: $0.397(0.252-0.541) p<0.001)$.

Conclusions $\mathrm{CT}$ is a reliable tool for assessing the extent of the disease in $\mathrm{AOC}$, but it has limitations in predicting surgical outcome. This study was unable to show an association between the CT-PCI and surgical outcome when the data were adjusted and ascites, CA-125 level, days between the CT examination to surgery and CPLN. Ascites volumes exceeding $1000 \mathrm{ml}$ increased the risk of residual disease and thereby worse outcome. That certain areas (e.g., small bowel region) are particularly critical when evaluating surgical outcome using preoperative CT-PCl warrants further investigation.

\section{Background}

Epithelial ovarian cancer is the gynecological malignancy with the highest mortality rate with five-years survival rate below $45 \%$ [41]. More than $70 \%$ of ovarian cancer cases are diagnosed at advanced stages after having spread throghout the abdominal cavity [37]. Advanced ovarian cancer (AOC) is generally found in the omentum, the peritoneal surfaces from the diaphragm to the pouch of Douglas, due to ascites formation and circulation in the abdominal cavity [8]. 
The standard treatment for $\mathrm{AOC}$ is primary debulking surgery (PDS) followed by platinum-based postoperative chemotherapy [29]. Since surgery is the only way to improve prognosis for patients with AOC, the abdominal tumor burden must be well characterized to effectively plan the surgery and achieve maximal radicality. Preoperative computed tomography (CT) examination of the patient to characterize the tumor spread is standard procedure. Another way to characterize the tumor burden is through visual quantification of the tumor in the peritoneal cavity $(\mathrm{PCl})$, first described by Sugarbaker in 1998 for colorectal cancer[15, 38,44]. A high peritoneal cancer index (PCI) indicates a worse surgical outcome and suggests considering other treatment options for the patient than primary surgery $[10,22]$. $\mathrm{PCl}$ in $\mathrm{AOC}$ has not been used outside clinical of studies. Likewise, PCl estimation from a preoperative CT scan (CT-PCI) is not part of standard guidelines for ovarian cancer diagnostics, but previous studies on CT-PCl in ovarian cancer have shown a significant relationship between CT-PCl and suboptimal surgery,postoperative complications and OS[20,35].

Investigators have tried to find the optimal benefit of preoperative CT scan to identify radiological predictors[21, 32]. Along with the development of the imagining technique, markers, like cardiophrenic lymph nodes (CPLNs) have been identified in patients with AOC[34].CPLN metastases are associated with impaired PFS and OS in patients with AOC $[24,30]$. To our knowledge, there is no clear-cut evidence that removing the lymph node leads to better OS eller PFS in AOC [34].

CA-125 is a high molecular weight glycoprotein,expressed in a large number of diseases and by a large proportion of epithelial ovarian cancer cases, with poor specificity and sensibility [26]. Several studies have tried to predict surgical outcomes using CA-125 in AOC, with inconsistent results $[7,25,27,39]$.

This study aimed to investigate if preoperative imaging (CT-PCl, ascites, and CPLN) is associated with the surgical outcome, toward detecting cases that are not well suited for surgery. To optimize prognosis, surgery for AOC should reach macroscopic radicality [11]. Since there are no known preoperative markers specific to a negative surgical outcome, the purpose of this study was to identify factors that predict which cases are not suitable for extensive surgery. $u$

\section{Methods}

\subsection{Patient's characteristics}

A total of 194 patients with AOC (FIGO stage IIIB-IVB) were diagnosed and treated from January 2016 to December 2018 at Skåne University Hospital, a tertiary center for gynecologic cancer treatment for the 1.6 million inhabitants in Southern Sweden. Patient data were collected retrospectively from the patients' medical reports. Patients receiving neoadjuvant chemotherapy with interval debulking surgery (33 patients, $17 \%$ ) or with palliative chemotherapy only (15 patients, $7.7 \%$ ) were excluded. 27 patients were excluded due to insufficient data. 119 patients deemed suitable for upfront extensive surgery were included in the study.

Patient characteristics are shown in Table 1. 
Table 1. Patient`s characteristics 


\begin{tabular}{|c|c|c|}
\hline Characteristics & No. & (\%) \\
\hline All cases & 119 & 100 \\
\hline Age median (range) years & $66.8(28-89)$ & \\
\hline \multicolumn{3}{|l|}{ ECOG } \\
\hline $0-1$ & 94 & 79 \\
\hline$\geq 2$ & 25 & 21 \\
\hline \multicolumn{3}{|l|}{ Albumin } \\
\hline$\geqq 30 \mathrm{~g} / \mathrm{L}$ & 100 & 84 \\
\hline$<30 \mathrm{~g} / \mathrm{L}$ & 19 & 16 \\
\hline \multicolumn{3}{|l|}{ FIGO } \\
\hline IIIB & 10 & 8.4 \\
\hline IIIC & 80 & 67.2 \\
\hline IVA & 13 & 10.92 \\
\hline IVB & 16 & 13.4 \\
\hline \multicolumn{3}{|l|}{ Histology } \\
\hline High-grade serous & 100 & 85.47 \\
\hline Low-grade serous & 9 & 7.7 \\
\hline Endometrioid & 5 & 4.27 \\
\hline Mucinous & 1 & 0.85 \\
\hline Carcinosarcoma & 2 & 1.7 \\
\hline Squamous cell carcinoma & 1 & 0.845 \\
\hline CA-125 median (range) & $\begin{array}{l}896 \\
10000)\end{array}$ & \\
\hline S-PCI median (range) & $16.5(2-38)$ & \\
\hline
\end{tabular}




\begin{tabular}{|c|c|c|}
\hline & & \\
\hline PCI 1-10 & 28 & 2352 \\
\hline PCI11-20 & 53 & 44.53 \\
\hline $\mathrm{PCI} \geq 21$ & 38 & 31.93 \\
\hline CT-PCI median(range) & $17(0-36)$ & \\
\hline PCI 1-10 & 30 & 25.21 \\
\hline PCI 11-20 & 40 & 33.61 \\
\hline PCI $>21$ & 49 & 41.18 \\
\hline S-Ascites (ml) & & \\
\hline$<500$ & 56 & 47.1 \\
\hline$\geq 500-<1000$ & 4 & 3.4 \\
\hline$\geq 1000$ & 32 & 16 \\
\hline Paracentesis & 16 & 13.4 \\
\hline Missing & 11 & 9.2 \\
\hline CT-Ascites & & \\
\hline$<499$ & 70 & 58 \\
\hline $500-999$ & 8 & 6.7 \\
\hline$>1000$ & 21 & 17.6 \\
\hline Paracentesis & 16 & 13.4 \\
\hline Missing & 4 & 3.4 \\
\hline Duration of surgery (range) min & $335(98-712)$ & \\
\hline Residual tumor & & \\
\hline CCS & 75 & 63 \\
\hline OCS & 25 & 21 \\
\hline SCS & 19 & 16 \\
\hline Days between CT and surgery & $32(1-160)$ & \\
\hline
\end{tabular}




\begin{tabular}{|l|l|l|} 
(range) & & \\
\hline CPLN & 59 & \\
Negative $(<5 \mathrm{~mm})$ & 60 & 49.6 \\
Positive $(\geq 5 \mathrm{~mm})$ & & 50.4 \\
& & \\
\hline Diaphragm carcinomatosis & 27 & 22.7 \\
No & 84 & 70.6 \\
Yes & 6 & 6.7 \\
Missing data & & \\
\hline
\end{tabular}

CT-PCI computer tomography peritoneal carcinomatosis index, S-PCI surgical peritoneal carcinomatosis index, CCS complete cytoreductive surgery, OCS optimal cytoreductive surgery, SCS suboptimal cytoreductive surgery, FIGO, Fédération Internationale de Gynécologie Obstétrique, CPLN cardiophrenic lymph node

\subsection{Survival Analyses}

The patients were divided into three groups according to residual postoperative disease (residual disease $=0$, residual disease $<10 \mathrm{~mm}$, and residual disease $\geq 10 \mathrm{~mm}$ ). Kaplan-Meier curves were generated for each of the three groups and the OS from the groups with residual disease were compared with the group with no residual disease.

\subsection{Assessment of operability, resectability, and the postoperative residual disease}

Operability and resectability were evaluated for each patient according to age, medical history, symptoms, medication, social and nutritional status and feasibility of tumor debulking according to preoperative CT of the abdomen and thorax. This study was intended to evaluate the accuracy of CT using a quantitative assessment of the tumor burden performed by a radiologist (CT-PCI) and to compare this with the surgical PCl (S-PCl) determined by the surgeon at the beginning of the surgery. Only patients intended for upfront surgery were included since correlation between residual disease at the end of the surgery and survival, was shown primary in upfront situations [11]. The surgical outcome is indicated by the amount of residual disease after the surgery. The best outcome is complete cytoreductive surgery (CCS). Optimal cytoreductive surgery (OCS) indicates the residual disease under $10 \mathrm{~mm}$, and suboptimal cytoreductive surgery (SCS) results in $10 \mathrm{~mm}$ or more of residual disease. The surgical PCl, the amount of ascites, surgery duration and the presence of residual disease were extracted from the surgical reports. The 
volume of the ascites present at the surgery was categorized into groups $(<500 \mathrm{ml}, 500$ to $1000 \mathrm{ml}$, and $\geq 1000 \mathrm{ml}$ ). 23 of 119 patients underwent paracentesis because of abdominal swelling or tightness. Data from 10 patients were incomplete. The FIGO stage, tumor histology, and preoperative CA-125 levels were recorded.

\subsection{Assessment Of Tumor Extent}

To ensure the accuracy of the surgical documentation and S-PCl, both were performed by the same surgeon for a series of 25 patients of the cohort. The author calculated the PCl score for 25 surgical records and this was compared with the original $\mathrm{PCl}$ score calculated by the surgeon for each case. The mean and SD of the original S-PCI was $1.077 \pm 9.406$, and the newly calculated one was $16.231 \pm 9.035$, showing a very good correlation with the original measurement. Based on these findings, the remaining cases were assessed according to the $\mathrm{PCl}$ contained in the original surgical reports. The $\mathrm{PCl}$ score developed by Sugarbaker (1998) was used to quantify both CT-PCI and S-PCI[38]. The 13 abdominal regions were assessed for tumor content and scored from 0 to 3 depending on the tumor size, with a final sum ranging from 1 to 39 points. The results were categorized into three levels: $1-10,11-20, \geq 21$ points.

To evaluate the possible effect of time on the relationship between CT and surgery, CT-PCI was assessed within 20 days as a reference, which was related to $21-40$ days and more than 40 days. The 20 day interval was chosen as a reference regarding the actual standardized cancer care pathway in Sweden, which requires a maximum of 24 days until the start of treatment [18]. The median time between the CT and the surgery was 31.76 days (1-160). In this study, patients with prolonged time intervals were not excluded, rather, the data were categorized in three intervals.

\subsection{Image Analysis}

All eligible patients underwent CT in the supine position with intravenous and oral contrast. Digital CTimages were by convention reformatted in the coronal and sagittal planes. Since the images spanned several years, there was a variety of radiology systems; this has, however, been showed not to affect the detection of peritoneal carcinomatosis[6]. CT-PCI was retrospectively scored using the Sugarbaker classification $[12,15]$ by one of two radiology specialists (HS or JB). The CT-PCI was calculated as the sum of the numerical lesion scores assigned to the 13 abdominopelvic regions, and the lesion score to the largest visible implant. Ascites (three groups) were qualitatively estimated by one of two radiologists (HS or JB) concurrent with the CT-PCl evaluation. CPLN was retrospectively assessed by one of two radiology specialists (SP or NOW). CPLN was defined as a pathological enlargement measuring $\geq 5 \mathrm{~mm}$ the short axis in the axial plane [30] and was scored as negative (i.e., normal) or positive (i.e., enlarged).

\subsection{Statistical Analyses}

For descriptive data including means, medians and percentages, standard analyses were used. The Stata SE (version 16.0. College Station, Texas: StataCorp), and R studio were used for all statistical analyses. 
Kaplan Meyer analyses were used for survival analyses by dividing the patients into three groups according to their surgical outcome (SCS, OCS and CCS).

Linear and logistic regression analyses were used to determine the relationships between S-PCl, CT-PCl, and surgical outcome. We adjusted the data for different variables (ascites, CPLN, CA-125). Some data were log transformed due to asymmetric distribution.

Linear and logistic regression analyses were used to determine the impact of positive radiological CPLN on the surgical outcome (regarding the residual disease at the end of the surgery). We compared the presence or absence of CPLN, dichotomized and continuous. The results are presented as odds ratios (OR) with 95\% confidence interval (Cl).

Linear regression and interclass correlation (ICC) analyses were used to characterize the agreement between $\mathrm{CT}-\mathrm{PCl}$ (continuous) and S-PCl (continuous). We adjusted the data for CA-125 level (continuous), ascites (grouped into three categories : $<500 \mathrm{ml}, 500$ to $1000 \mathrm{ml}$, and $\geq 1000 \mathrm{ml}$ ) and the number of days between the CT examination and surgery (grouped into three categories : $<20$ days, 20-39 days, and $\geq 40$ days). An ICC analyses was used to compare S-ascites and CT-ascites (nominal) and weighted kappa and percent agreement were calculated. Kappa value was used to compare the agreement between those two groups (S-ascites and CT-ascites, both divided in three intervals $:<500 \mathrm{ml}, 500-1000 \mathrm{ml}$ and $\geq$ $1000 \mathrm{ml}$ ). A kappa values of $=1.00$ is reflective of perfect agreement, 0 indicates no agreement, 0.81-1.00 shows very good agreement, and $0.61-0.80$ good agreement.

\section{Results}

\subsection{Survival analysis}

Kaplan-Meier curve estimates the probability of OS for patients with CCS (residual disease RD $=0 \mathrm{~mm})(\mathrm{n}$ $=71), \operatorname{OCS}(\operatorname{RD}<10 \mathrm{~mm})(\mathrm{n}=23)$ and SCS $(\operatorname{RD} \geq 10 \mathrm{~mm})(\mathrm{n}=17)$ (Fig. 1).

The survival of patients with complete resection was significantly increased compared with the OCS ( $p<$ $0.03)$ and SCS groups $(p<0.005)$.

\subsection{Effects of S-PCl, CT-PCl, ascites, CA-125, and CPLN on surgical outcome}

Results from linear the regression models showed a significant association between $\mathrm{S}-\mathrm{PCl}$ and surgical outcome (OR 1.240 (1.141-1.348), $p<001)$.

In the unadjusted analyses, there was a significant association between preoperative assessment of CT$\mathrm{PCl}$ and the surgical outcome (OR $1.008(1.037-1.141), \mathrm{p}<0.001)$. When the results were adjusted for CA125 level, CPLN, and ascites, the association was no longer significant (OR $046(0.987-1.108), p<0.128)$ (Table 2).

Table 2. Preoperative evaluation of the surgical outcome (residual disease $\geq 10 \mathrm{~mm}$ ) 


\begin{tabular}{lllll}
\hline & A & \multicolumn{1}{l}{ B } & \\
VARIABLES & OR $(95 \% \mathrm{CI})$ & $\mathrm{p}$-val & $\beta(95 \% \mathrm{CI})$ & $\mathrm{p}$-val \\
\hline CT-PCI & $1.088(1.037-1.141)$ & $<0.001$ & $1.046(0.987-1.108)$ & 0.128 \\
\hline $\log 2(\mathrm{CA}-125)$ & $1.279(1.017-1.608)$ & 0.036 & $0.981(0.695-1.386)$ & 0.914 \\
\hline CPLN & $1.742(0.820-3.701)$ & 0.149 & $1.202(0.446-3.239)$ & 0.716 \\
\hline CT-ascites $(\mathrm{ml})$ & & 0.001 & & 0.019 \\
\hline$<500$ & Ref. & & Ref. & \\
\hline $500-1000$ & $4.000(0.888-18.009)$ & & $2.990(0.578-15.468)$ & \\
\hline$\geq 1000$ & $8.000(2.717-23.555)$ & $5.626(1.665-19.007)$ & \\
\hline
\end{tabular}

A: Unadjusted analysis of each variable alone.

B: Adjusted model including all variables in the table.

When the value of 20 was used as a cut-off for S-PCl, 14 of 17 patients with suboptimal surgeries (RD $\geq$ $10 \mathrm{~mm}$ ) were identified. This gives a sensitivity of $82.35 \%$ and a specificity of $74 \%$. When the same cutoff point was used for $\mathrm{CT}-\mathrm{PCl}, 11$ of 17 patients with suboptimal surgeries were identified giving a sensitivity of $64,4 \%$ and a specificity of $61 \%$.

To identify the reason for the unresectability, the group of 19 patients with residual disease $\geq 10 \mathrm{~mm}$ was analyzed according to the site of this residual disease and the other reasons for terminating the surgery. 12 cases involved small intestine carcinomatosis and, in 9 of these, the intestinal carcinomatosis was referred to abdominal regions 9 to 12 (i.e., the small intestine) on the CT scan.

The preoperative amount of ascites, measured by CT, was significantly associated with a negative surgical outcome, defined as suboptimal cytoreductive surgery (for ascites $\geq 1000 \mathrm{ml}$ (OR 5.626 (1.66519.007), $p<0.019$ ) (Table 2).

CA-125 level was related to the surgical outcome by increasing the risk of suboptimal surgery by $28 \%$ (OR 1.278 (1.017-1.608), $(p<0.036)$, when the CA-125 value was doubled. However, this result was no longer statistically significant when adjusted for CT-PCI, CPLN, and ascites (OR $0.981(0.695-1.386)(p<0.914)$. The presence of CPLN was not correlated with the amount of residual disease at the end of the surgery in both the unadjusted and adjusted analyses (Table 2).

3.3 Preoperative assessment of tumor spread using preoperative CT-scan (CT-PCI and CT-ascites) and CA125 
Linear regression analysis revealed a significant association between increasing CT-PCl and the S-PCl (95\%) Cl: 0.511 (0.387-0.639), p < 0.001 (Fig. 2) representing a positive relationship between CT-PCl and $\mathrm{S}-\mathrm{PCl}$ (both continuous data). Statistical significance was maintained when the data were adjusted for CA-125 level, ascites and time between the CT scan and surgery (95\%) Cl: $0.397(0.252-0.541) p<0.001)$ (Table 3).

\section{Table 3. PCI surgery relative to CT-PCI, CA-125, ascites, and the time interval between the CT examination and the surgery.}

\begin{tabular}{|c|c|c|c|c|}
\hline & $\mathrm{A}$ & & $\mathrm{B}$ & \\
\hline VARIABLES & $\beta(95 \% \mathrm{CI})$ & $\mathrm{p}$-value & $\beta(95 \% \mathrm{CI})$ & p-value \\
\hline CT-PCI & $0.511(0.387-0.636)$ & $<0.001$ & $0.397(0.252-0.541)$ & $<0.001$ \\
\hline $\log 2(\mathrm{CA}-125)$ & $1.439(0.665-2.212)$ & $<0.001$ & $-0.040(-0.840-0.760)$ & 0.921 \\
\hline Days from CT to operation & & 0.001 & & 0.021 \\
\hline$<20$ & Ref. & & Ref. & \\
\hline $20-39$ & $6.019(2.630-9.408)$ & & $3.163(0.230-6.097)$ & \\
\hline$\geq 40$ & $7.179(3.277-11.080)$ & & $4.678(1.260-8.097)$ & \\
\hline Ascites CT (ml) & & $<0.001$ & & 0.038 \\
\hline$<500$ & Ref. & & Ref. & \\
\hline $500-1000$ & $6.121(0.807-11.436)$ & & $2.542(-2.147-7.231)$ & \\
\hline$\geq 1000$ & $7.842(4.288-11.395)$ & & $4.390(1.027-7.753)$ & \\
\hline
\end{tabular}

A: Unadjusted analysis of each variable alone.

B: Adjusted model including all variables in the table.

Using ICC to compare CT-PCI and S-PCI divided into three groups $(<11,11-20, \geq 21)$ also showed good agreement (95\%) Cl: 0.580 (0.442-0.691), 79\% agreement (Table 4).

Table 4. The relationship between CT-PCI and S-PCI. 


\begin{tabular}{llll}
\hline \multicolumn{4}{c}{ S-PCI } \\
\hline CT-PCI & $<11$ & $11-20$ & $\geq 21$ \\
\hline$<11$ & 18 & 9 & 1 \\
$11-20$ & 11 & 22 & 19 \\
$\geq 21$ & 1 & 8 & 30 \\
\hline
\end{tabular}

Intra class correlation (ICC) (95\%): 0.580(0.442-0.691)

Weighted kappa: 0.491

Percent agreement: $79 \%$

The amount of ascites was positively correlated with S-PCI in both the unadjusted and adjusted data (for ascites volume > $1000 \mathrm{ml}$ : (95\%) Cl: $4.390(1.027-7.753) \mathrm{p}<0.038)($ Table 3). When S-ascites and CTascites were compared, the weighted kappa value was 0.678 , indicating good conformity $(86 \%$ agreement) (Table 5).

Table 5. The agreement between CT-ascites and S-ascites.

\begin{tabular}{llll}
\hline \multicolumn{4}{c}{ Ascites surgery } \\
\hline Ascites CT & $<500 \mathrm{ml}$ & $500-1000 \mathrm{ml}$ & $\geq 1000 \mathrm{ml}$ \\
\hline$<500 \mathrm{ml}$ & 51 & 2 & 4 \\
$500-1000 \mathrm{ml}$ & 0 & 1 & 7 \\
$\geq 1000 \mathrm{ml}$ & 3 & 1 & 17 \\
\hline
\end{tabular}

Weighted kappa: 0.678

Percent agreement: $86 \%$

CA-125 level was related to tumor burden in the non-adjusted data $(1.439(0.665-2.212), p<0.001)$ but when the data were adjusted for CT-PCl, ascites, and days between CT examination and surgery, no significant association was found (95\%) Cl: $-0.040(-0.840-0.760) \mathrm{p}<0.921)($ Table 3$)$.

\subsection{CPLN}

$50.4 \%(n=60)$ of the patients exhibited CPLNs $\geq 5 \mathrm{~mm}$ in the short axis of the CT scan. In $46 \%(n=56)$, the dominant lymph node was located on the anterior side of the cardiophrenic space, whereas in $22 \%$ ( $n$ $=27$ ) of the patients, it was located on the posterior side. 23 patients had enlarged lymph nodes on both the anterior and posterior sides. A median of 1.17 (range 0-6) enlarged CPLNs was detected. 
The surgical outcome was not affected by enlarged CPLNs present on the CT images (OR 1.742, (95\%) Cl: $0.820-3.701), p<0.149)$, nor by the number of enlarged CPLNs (OR 1.139, (95\%) Cl: 0.896-1.447) (Table 6).

\section{Table 6.}

The relationship between the surgical outcome and CPLN

\begin{tabular}{|l|l|lc|l|}
\hline Variables & \multicolumn{1}{|c|}{ OR } & CI & 95\% & value \\
\hline Number of CPLN & 1.139 & 1.447 & $0.896-$ & 0.289 \\
\hline $\begin{array}{l}\text { Presence of } \\
\text { CPLN/yes }\end{array}$ & 1.742 & 3.701 & $0.820-$ & 0.149 \\
\hline
\end{tabular}

\section{Discussion}

The preoperative estimation of tumor spread and its resectability are both of great importance to surgical outcome in AOC. In this study, poor surgical outcome, defined as residual disease $\geq 10 \mathrm{~mm}$, was strongly connected with S-PCl (one unit on the S-PCl increased unresectability risk by $24 \%$ ), which is in accordance with studies on colorectal and ovarian cancer $[10,19,28]$. Llueca et al tried to establish a predictive model for unresectability using CT, laparoscopy, and laparotomy. The authors concluded that the best cut-off for predicting SCS with $\mathrm{PCl}>20$ for the three diagnostic techniques, with a $91 \%$ specificity and $27 \%$ sensitivity for the CT scan [23]. In this study, a cut-off value of 20 on the S-PCl, identified $82 \%$ patients with SCS with a specificity of $74 \%$. The same cut-off value for CT-PCl, detected $64 \%$ of the cases. The sensitivity was slightly lower for CT-PCl, however, the number of patients with macroscopic residual disease above $10 \mathrm{~mm}$ was considerably lower than the number of patients with CCS. Jönsdottir et al. studied the correlation between S-PCl and surgical outcome and found a PCl cut-off of 24. In their study $62 \%$ of patients with $\mathrm{PCl}$ above 24 had an unsatisfactory surgical outcome defined as SCS. The authors conclude that neoadjuvant chemotherapy could be considered if the $\mathrm{PCl}$ is higher than 24 .Theis study just emphasizes the reasons underlying SCS but has no predictive value for SCS or open-close surgery [16].

If preoperative CT-PCl could mimic the operative S-PCl, it would be an excellent tool for assessing the resectability of a tumor, since S-PCI is a good indicator of OS, $[4,19]$. In the present study, CCS resulted in a significantly longer OS compared with patients with residual disease $<10 \mathrm{~mm}$ and those with suboptimal debulking (residual disease $\geq 10 \mathrm{~mm}$ ), in line with previous studies $[5,11]$. This study intended to elucidate whether patients with residual disease over $10 \mathrm{~mm}$ could be identified preoperatively, since CT-PCl correlated with intraoperative $\mathrm{PCl}(\mathrm{S}-\mathrm{PCl})$. When the CT-PCl value was high $\mathrm{PCl}, \mathrm{S}-\mathrm{PCl}$ was high $\mathrm{PCl}$ as well. In the non-adjusted data, CT-PCl correlated well with surgical outcome, which is in agreement with other studies, but when we adjusted to CA-125 level, ascites, and CPLN, the 
association between CT-PCl and the surgical outcome became non-significant. It could be that the groups of patients with macroscopic residual disease left were small relative to the group of patients with complete resection. Avesani et al. (2020) found a strong correlation between the CT-PCl and residual disease of any size at the end of the surgery. This was probably due to a different patient population with a substantial amount (24\%) of patients included from early FIGO stages (I and II) and different data analyses.

Nevertheless, our study failed to demonstrate a statistically significant relationship between surgical outcome and CT-PCl, enlarged CPLN (measured by CT scan), or CA-125 level. On the other hand, CT-PCI still correlate to S-PCl, when the results were adjusted to CA-125 level, ascites, and the time interval between $\mathrm{CT}$ and the surgery.

Some studies have analyzed $\mathrm{PCl}$ regions separately and found that certain areas are more related to unresectability. Regions $9-12$, corresponding to the small intestine, were significantly more predictive of residual disease than the entire PCI [31]. The same trend was found in the present study in the SCS group, 12 patients exhibited small intestine carcinomatosis. Nine (75\%) of them had small intestinal carcinomatosis, correctly predicted from the CT scan.

The quantitation of ascites has, to our knowledge, never been evaluated in preoperative CT scans in patients with AOC. In this study, the CT based evaluation of ascites volume correlated with the ascites volume determined intraoperatively. Others have found that, in the intraoperative quantification of ascites, a large volume correlate with unresectability and worse PFS and OS $[2,40]$. In the recurrent situation too, ascites is a negative predictor of surgical success [14]. Massive ascites evaluated by CT scan also correlated with increased SCS risk in the present study. A three-fold increased risk for unresectability in CT-quantified ascites over $500 \mathrm{ml}$ was found; furthermore, in ascites over $1000 \mathrm{ml}, 5.6$-fold more patients had residual disease exceeding $\geq 10 \mathrm{~mm}$.

In addition to CT, recent imaging studies also include FDG-PET/CT and MRI. A systematic review of five studies (544 participants) addresses the ability of FDG-PET/CT and MRI to predict SCS. Both FDGPET/CT and MRI showed high specificity with moderate sensitivity [32]. Due to the small sample size of the studies and the lack of sensitivity, the quality of the evidence was fairly low. A study by Schmidt et al. establish CT, MRI, and PET-CT as reliable instrument for the evaluation of intraoperative PCI[36]. Some evidence supports the use of ultrasonography in the preoperative staging of $\mathrm{AOC}$; for example, as shown by Weinberger et al. for the detection of pelvic carcinomatosis [42, 45]. Preoperative tumor staging in AOC by laparoscopy is standard procedure in some centers but carries some disadvantages including invasiveness and lack of full visualization [13]. The patients were exposed to a large scale surgery with risks of complications and a FIGO stage migration due to tumor infiltration into the abdominal wall [3, 43]. Incomplete visualization of the abdominal cavity might result in an incorrect assessment of the tumor burden due to difficulties in inspecting certain abdominal regions [1]. Rutten et al. concluded that diagnostic laparoscopy should not be considered standard procedure in clinical practice [33]. 
$\mathrm{CPLNs}$ in $\mathrm{AOC}$ are associated with carcinomatosis in the upper abdomen, diaphragmatic carcinomatosis, and a worse prognosis regardless of the surgical removal during the cytoreductive surgery. Prader et al. analyzed 350 patients, of which almost $40 \%$ had negative CPLNs while the rest had radiologically positive CPLNs. In patients with macroscopically completely resected tumors, CPLN metastases were associated with reduced PFS and OS. Still, the role of the CPLN resection remains unclear [30]. In this study, the CT-PCI for patients with radiologically enlarged CPLN was more than doubled for SCS group (nevertheless, not statistically significant), and no correlation was found between the presence of CPLNs on CT images and the surgical outcome.

A relationship between CA-125 level and surgical outcome is controversial. Many studies have found a correlation between CA-125>500 U/mL and suboptimal cytoreduction $[7,9,17,25,39]$. The data analyzed in the present study indicated study a positive relationship between high CA-125 level the amount of residual, for every duplication of CA-125, the OR for the remaining tumor tissue increased by $28 \%$ (unadjusted data). When the data were adjusted for CT-PCI, ascites, and CPLN, no significant association between CA-125 level and the surgical outcome was found.

\section{Conclusions}

Numerical estimation of the tumor spread by CT is feasible but requires a technically skilled radiologist who has mastered the evaluation of the different abdominal areas in the abdomen. Based on the findings of the present study, CT-PCl alone does not predict the surgical outcome in this study, but correlated well with increasing surgical $\mathrm{PCl}$, which is a marker of worse surgical outcome. That certain abdominal areas, (e.g., small bowel region) strongly associated with unresectability, should be investigated in further studies. Together with a high volume of ascites, as shown in this study, the CT-PCl count in essential areas of the abdomen might be a better indicator of surgical outcome than the total sum of CT-PCl in the abdominal cavity.

\section{Abbreviations}

OC: Ovarian cancer

AOC: Advanced ovarian cancer

PCl: Peritoneal cancer Index

CT: Computerized tomography

CT-PCl: PCl evaluated by CT

S-PCl: PCl evaluated during surgery

CCS: Complete cytoreductive surgery 
OCS: Suboptimal cytoreductive surgery

SCS: Suboptimal cytoreductive surgery

RT: rest tumor/residual disease

CPLN: Cardiophrenic lymph nodes

ECOG: Eastern Cooperation Oncology Group

OS: Overall survival

PFS: Progression-free survival

FIGO: International Federation of Obstetrics and Gynecology

\section{Declarations}

\section{Ethical declaration}

All patient data were handled according to the Word Medical Association's Declaration' 2008 Declaration of Helsinki and in compliance with national law. This study was approved by the Swedish Ethical Review Authority with apl.no.2019/00450.

\section{Consent for publication}

Not applicable

\section{Availability of data and materials}

The datasets used and/or analyzed in the present study are available from the corresponding author upon reasonable request.

\section{Competing interests}

The authors have no competing interest.

\section{Funding}

This study was supported by Regional Research Support for Southern Sweden.

\section{Author Contribution}

Mihaela Asp is the main contributor to the study design, data collection, data interpretation, and manuscript writing. Hanna Sartor is the main contributor to the CT data collection and participated in designing the study, data interpretation and manuscript revision. Päivi Kannisto coordinated and 
contributed to the study design and manuscript revision. Susanne Malander provided oncological expertise and manuscript revision. NilsOlof Wallengren, Sonja Pudaric and Johan Bengtsson collected and interpreted the CT data. All of the authors read and approved the final manuscript.

\section{References}

1. Angioli R, Palaia I, Zullo MA, Muzii L, Manci N, Calcagno M, Panici PB: Diagnostic open laparoscopy in the management of advanced ovarian cancer. Gynecol Oncol 2006, 100(3):455-461.

2. Arab M, Jamdar F, Sadat Hosseini M, Ghodssi- Ghasemabadi R, Farzaneh F, Ashrafganjoei T: Model for Prediction of Optimal Debulking of Epithelial Ovarian Cancer. Asian Pac J Cancer Prev 2018, 19(5):1319-1324.

3. Ataseven B, Grimm C, Harter P, Heikaus S, Heitz F, Traut A, Prader S, Kahl A, Schneider S, Kurzeder C et al: Prognostic Impact of Port-Site Metastasis After Diagnostic Laparoscopy for Epithelial Ovarian Cancer. Ann Surg Oncol 2016, 23(Suppl 5):834-840.

4. Avesani G, Arshad M, Lu H, Fotopoulou C, Cannone F, Melotti R, Aboagye E, Rockall A: Radiological assessment of Peritoneal Cancer Index on preoperative CT in ovarian cancer is related to surgical outcome and survival. Radiol Med 2020, 125(8):770-776.

5. Babayeva A, Braicu El, Grabowski JP, Gasimli K, Richter R, Muallem MZ, Sehouli J: Clinical Outcome After Completion Surgery in Patients With Ovarian Cancer: The Charite Experience. Int J Gynecol Cancer 2018, 28(8):1491-1497.

6. Chandrashekhara SH, Thulkar S, Srivastava DN, Kumar L, Hariprasad R, Kumar S, Sharma MC: Preoperative evaluation of peritoneal deposits using multidetector computed tomography in ovarian cancer. The British journal of radiology 2011, 84(997):38-43.

7. Chi DS, Venkatraman ES, Masson V, Hoskins WJ: The ability of preoperative serum CA-125 to predict optimal primary tumor cytoreduction in stage III epithelial ovarian carcinoma. Gynecol Oncol 2000, 77(2):227-231.

8. Committee on the State of the Science in Ovarian Cancer R, Board on Health Care S, Institute of M, National Academies of Sciences E, Medicine. In: Ovarian Cancers: Evolving Paradigms in Research and Care. edn. Washington (DC): National Academies Press (US) Copyright 2016 by the National Academy of Sciences. All rights reserved.; 2016.

9. Cooper BC, Sood AK, Davis CS, Ritchie JM, Sorosky JI, Anderson B, Buller RE: Preoperative CA 125 levels: an independent prognostic factor for epithelial ovarian cancer. Obstet Gynecol 2002, 100(1):59-64.

10. da Silva RG, Sugarbaker PH: Analysis of prognostic factors in seventy patients having a complete cytoreduction plus perioperative intraperitoneal chemotherapy for carcinomatosis from colorectal cancer. J Am Coll Surg 2006, 203(6):878-886.

11. du Bois A, Reuss A, Pujade-Lauraine E, Harter P, Ray-Coquard I, Pfisterer J: Role of surgical outcome as prognostic factor in advanced epithelial ovarian cancer: a combined exploratory analysis of 3 
prospectively randomized phase 3 multicenter trials: by the Arbeitsgemeinschaft Gynaekologische Onkologie Studiengruppe Ovarialkarzinom (AGO-OVAR) and the Groupe d'Investigateurs Nationaux Pour les Etudes des Cancers de l'Ovaire (GINECO). Cancer 2009, 115(6):1234-1244.

12. Duhr CD, Kenn W, Kickuth R, Kerscher AG, Germer CT, Hahn D, Pelz JO: Optimizing of preoperative computed tomography for diagnosis in patients with peritoneal carcinomatosis. World J Surg Oncol 2011, 9:171.

13. Fagotti A, Ferrandina G, Fanfani F, Ercoli A, Lorusso D, Rossi M, Scambia G: A laparoscopy-based score to predict surgical outcome in patients with advanced ovarian carcinoma: a pilot study. Ann Surg Oncol 2006, 13(8):1156-1161.

14. Harter P, du Bois A, Hahmann M, Hasenburg A, Burges A, Loibl S, Gropp M, Huober J, Fink D, Schröder $W$ et al: Surgery in recurrent ovarian cancer: the Arbeitsgemeinschaft Gynaekologische Onkologie (AGO) DESKTOP OVAR trial. Ann Surg Oncol 2006, 13(12):1702-1710.

15. Jacquet $P$, Sugarbaker PH: Clinical research methodologies in diagnosis and staging of patients with peritoneal carcinomatosis. Cancer Treat Res 1996, 82:359-374.

16. Jónsdóttir B, Lomnytska M, Poromaa IS, Silins I, Stålberg K: The Peritoneal Cancer Index is a Strong Predictor of Incomplete Cytoreductive Surgery in Ovarian Cancer. Ann Surg Oncol 2020.

17. Kang S, Kim TJ, Nam BH, Seo SS, Kim BG, Bae DS, Park SY: Preoperative serum CA-125 levels and risk of suboptimal cytoreduction in ovarian cancer: a meta-analysis. Journal of surgical oncology 2010, 101(1):13-17.

18. Standardiserat vårdförlopp äggstockscancer, epitelial [https://kunskapsbanken.cancercentrum.se/diagnoser/aggstockscancer-epitelial/vardforlopp/]

19. Lampe B, Kroll N, Piso P, Forner DM, Mallmann P: Prognostic significance of Sugarbaker's peritoneal cancer index for the operability of ovarian carcinoma. Int J Gynecol Cancer 2015, 25(1):135-144.

20. Llueca A, Escrig J: Prognostic value of peritoneal cancer index in primary advanced ovarian cancer. Eur J Surg Oncol 2018, 44(1):163-169.

21. Llueca A, Serra A, Rivadulla I, Gomez L, Escrig J: Prediction of suboptimal cytoreductive surgery in patients with advanced ovarian cancer based on preoperative and intraoperative determination of the peritoneal carcinomatosis index. World J Surg Oncol 2018, 16(1):37.

22. Llueca A, Serra A, Rivadulla I, Gomez L, Escrig J, group Mw: Prediction of suboptimal cytoreductive surgery in patients with advanced ovarian cancer based on preoperative and intraoperative determination of the peritoneal carcinomatosis index. World J Surg Oncol 2018, 16(1):37.

23. Llueca A, Serra A, Delgado K, Maiocchi K, Jativa R, Gomez L, Escrig J: A radiologic-laparoscopic model to predict suboptimal (or complete and optimal) debulking surgery in advanced ovarian cancer: a pilot study. Int J Womens Health 2019, 11:333-342.

24. Luger AK, SteinkohI F, Aigner F, Jaschke W, Marth C, Zeimet AG, Reimer D: Enlarged cardiophrenic lymph nodes predict disease involvement of the upper abdomen and the outcome of primary surgical debulking in advanced ovarian cancer. Acta Obstet Gynecol Scand 2020, 99(8):1092-1099. 
25. Memarzadeh S, Lee SB, Berek JS, Farias-Eisner R: CA125 levels are a weak predictor of optimal cytoreductive surgery in patients with advanced epithelial ovarian cancer. Int J Gynecol Cancer 2003, 13(2):120-124.

26. Moss EL, Hollingworth J, Reynolds TM: The role of CA125 in clinical practice. J Clin Patho/ 2005, 58(3):308-312.

27. Obeidat B, Latimer J, Crawford R: Can optimal primary cytoreduction be predicted in advanced stage epithelial ovarian cancer? Role of preoperative serum CA-125 level. Gynecologic and obstetric investigation 2004, 57(3):153-156.

28. Pestieau SR, Sugarbaker PH: Treatment of primary colon cancer with peritoneal carcinomatosis: comparison of concomitant vs. delayed management. Dis Colon Rectum 2000, 43(10):1341-1346; discussion 1347-1348.

29. Piver MS: Treatment of ovarian cancer at the crossroads: 50 years after single-agent melphalan chemotherapy. Oncology (Williston Park) 2006, 20(10):1156, 1158.

30. Prader S, Vollmar N, du Bois A, Heitz F, Schneider S, Ataseven B, Bommert M, Waltering KU, Heikaus $\mathrm{S}$, Koch JA et al: Pattern and impact of metastatic cardiophrenic lymph nodes in advanced epithelial ovarian cancer. Gynecol Oncol 2019, 152(1):76-81.

31. Rosendahl M, Harter P, Bjørn SF, Høgdall C: Specific Regions, Rather than the Entire Peritoneal Carcinosis Index, are Predictive of Complete Resection and Survival in Advanced Epithelial Ovarian Cancer. International Journal of Gynecologic Cancer 2018, 28(2):316-322.

32. Roze JF, Hoogendam JP, van de Wetering FT, Spijker R, Verleye L, Vlayen J, Veldhuis WB, Scholten RJ, Zweemer RP: Positron emission tomography (PET) and magnetic resonance imaging (MRI) for assessing tumour resectability in advanced epithelial ovarian/fallopian tube/primary peritoneal cancer. Cochrane Database Syst Rev 2018, 10(10):Cd012567.

33. Rutten MJ, Leeflang MM, Kenter GG, Mol BW, Buist M: Laparoscopy for diagnosing resectability of disease in patients with advanced ovarian cancer. Cochrane Database Syst Rev 2014, 2014(2):Cd009786.

34. Salehi S, Mohammar R, Suzuki C, Joneborg U, Hjerpe E, Torbrand C, Falconer H: Cardiophrenic lymph node resection in advanced ovarian cancer: surgical outcomes, pre- and postoperative imaging. Acta oncologica (Stockholm, Sweden) 2018, 57(6):820-824.

35. Sartor H, Bjurberg M, Asp M, Kahn A, Brandstedt J, Kannisto P, Jirstrom K: Ovarian cancer subtypes and survival in relation to three comprehensive imaging parameters. J Ovarian Res 2020, 13(1):26.

36. Schmidt S, Meuli RA, Achtari C, Prior JO: Peritoneal carcinomatosis in primary ovarian cancer staging: comparison between MDCT, MRI, and 18F-FDG PET/CT. Clin Nucl Med 2015, 40(5):371-377.

37. Siegel RL, Miller KD, Jemal A: Cancer statistics, 2015. CA: a cancer journal for clinicians 2015, 65(1):5-29.

38. Sugarbaker PH: Management of peritoneal-surface malignancy: the surgeon's role. Langenbecks Arch Surg 1999, 384(6):576-587. 
39. Suidan RS, Ramirez PT, Sarasohn DM, Teitcher JB, lyer RB, Zhou Q, lasonos A, Denesopolis J, Zivanovic $\mathrm{O}$, Long Roche $\mathrm{KC}$ et al: A multicenter assessment of the ability of preoperative computed tomography scan and CA-125 to predict gross residual disease at primary debulking for advanced epithelial ovarian cancer. Gynecol Oncol 2017, 145(1):27-31.

40. Szender JB, Emmons T, Belliotti S, Dickson D, Khan A, Morrell K, Khan A, Singel KL, Mayor PC, Moysich KB et al: Impact of ascites volume on clinical outcomes in ovarian cancer: A cohort study. Gynecol Oncol 2017, 146(3):491-497.

41. Webb PM, Jordan SJ: Epidemiology of epithelial ovarian cancer. Best practice \& research Clinical obstetrics \& gynaecology 2017, 41:3-14.

42. Weinberger V, Fischerova D, Semeradova I, Slama J, Dundr P, Dusek L, Cibula D, Zikan M: Prospective Evaluation of Ultrasound Accuracy in the Detection of Pelvic Carcinomatosis in Patients with Ovarian Cancer. Ultrasound Med Biol 2016, 42(9):2196-2202.

43. Vergote I, Marquette S, Amant F, Berteloot P, Neven P: Port-site metastases after open laparoscopy: a study in 173 patients with advanced ovarian carcinoma. Int J Gynecol Cancer 2005, 15(5):776-779.

44. Witkamp AJ, de Bree E, Van Goethem R, Zoetmulder FA: Rationale and techniques of intra-operative hyperthermic intraperitoneal chemotherapy. Cancer Treat Rev 2001, 27(6):365-374.

45. Zikan M, Fischerova D, Semeradova I, Slama J, Dundr P, Weinberger V, Dusek L, Cibula D: Accuracy of ultrasound in prediction of rectosigmoid infiltration in epithelial ovarian cancer. Ultrasound Obstet Gynecol 2017, 50(4):533-538.

\section{Figures}

- CCR(rest tumor $=0$ ) $n=71 \cdots \operatorname{OCS}$ (rest tumor $<10 \mathrm{~mm}$ ) $n=23-\cdot \operatorname{SCS}$ (rest tumor $210 \mathrm{~mm}$ ) $n=17$

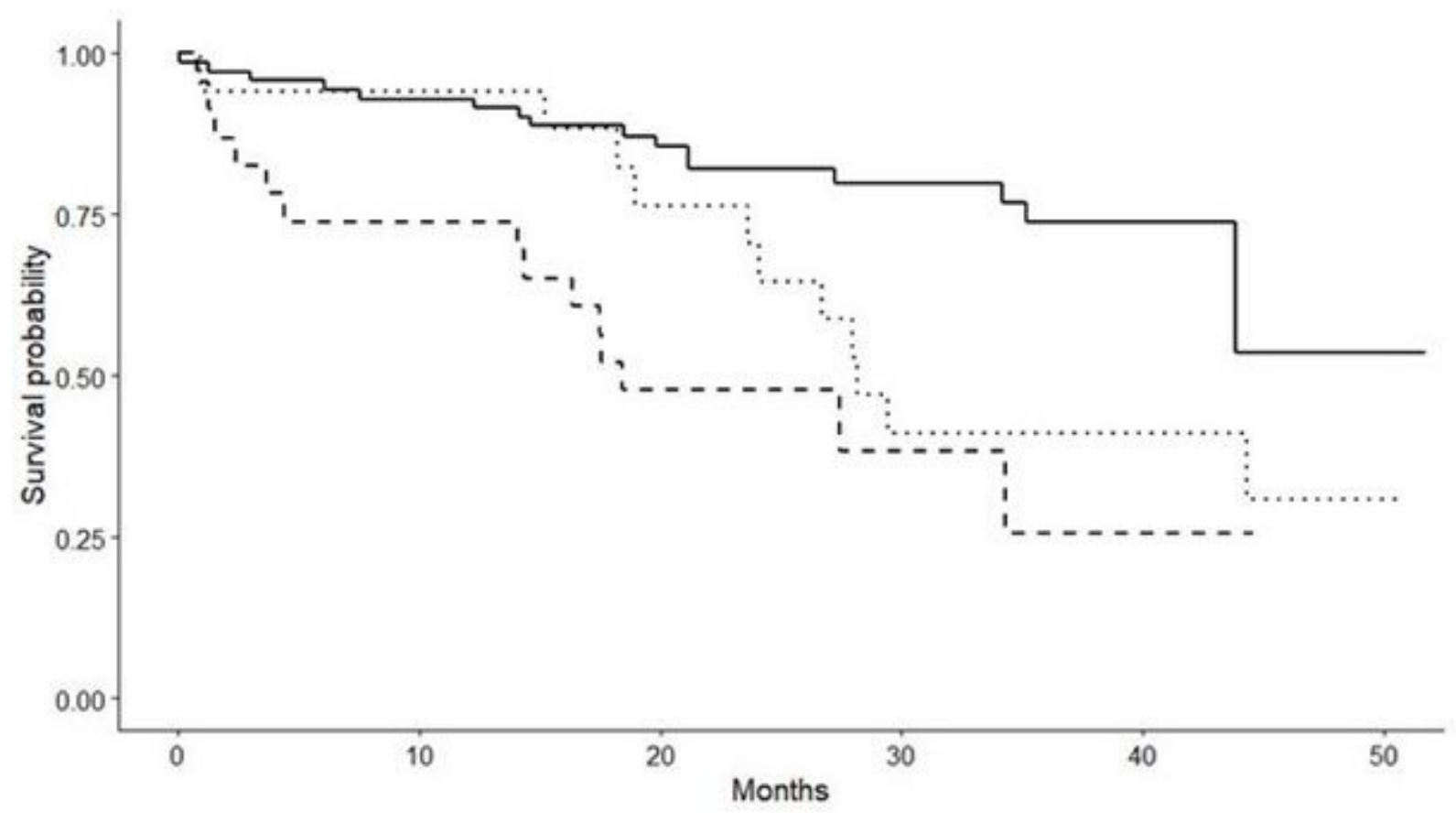

Figure 1 
Survival probability estimated by Kaplan-Meier curves for the entire cohort based on residual disease. Survival probability was significantly reduced for patients with SCS $p<0.005$ and OCS $p<0.03$ (log-rank test) relative to their CCS counterparts. Observation time indicated in month.

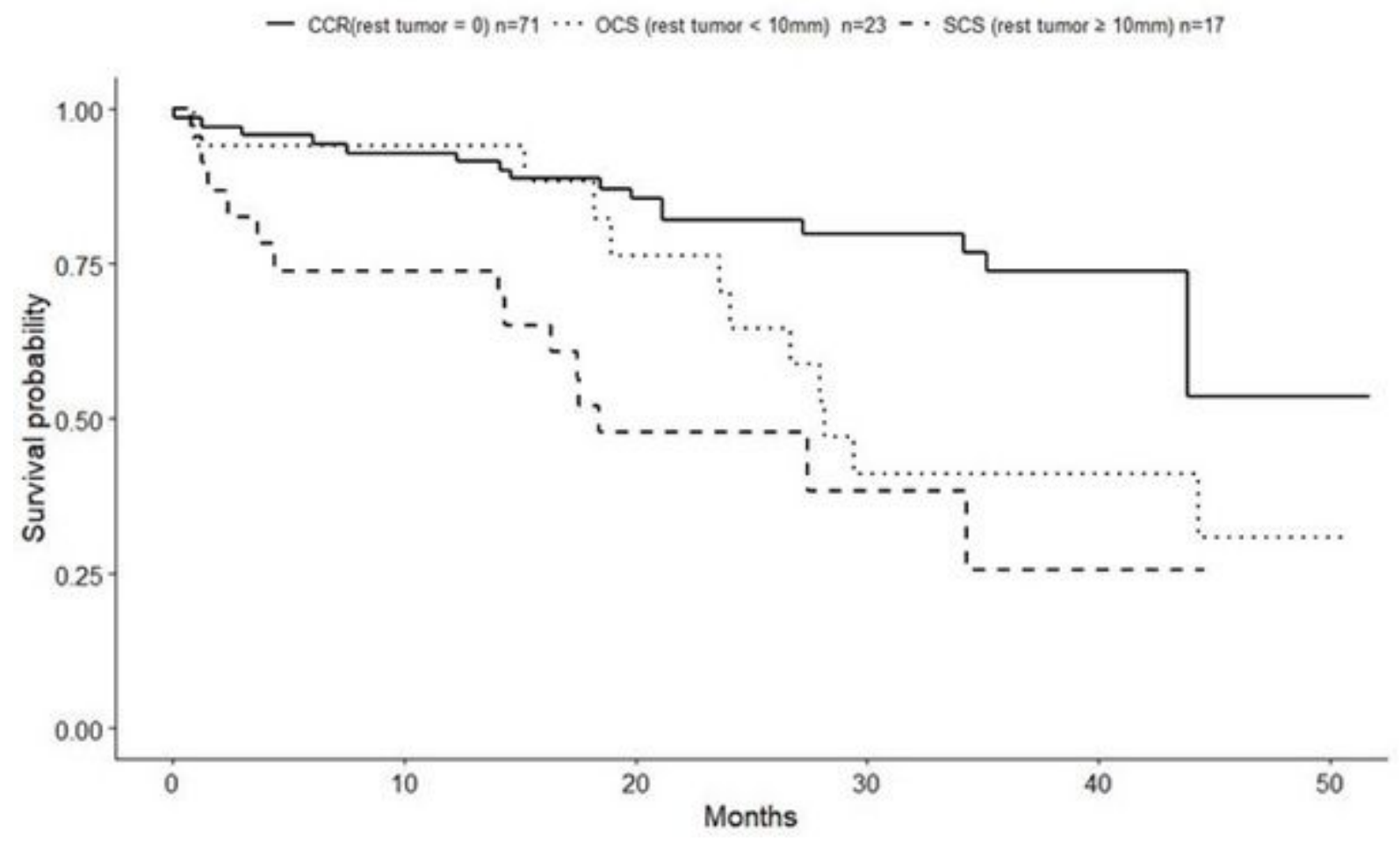

\section{Figure 1}

Survival probability estimated by Kaplan-Meier curves for the entire cohort based on residual disease. Survival probability was significantly reduced for patients with SCS $p<0.005$ and OCS $p<0.03$ (log-rank test) relative to their CCS counterparts. Observation time indicated in month. 


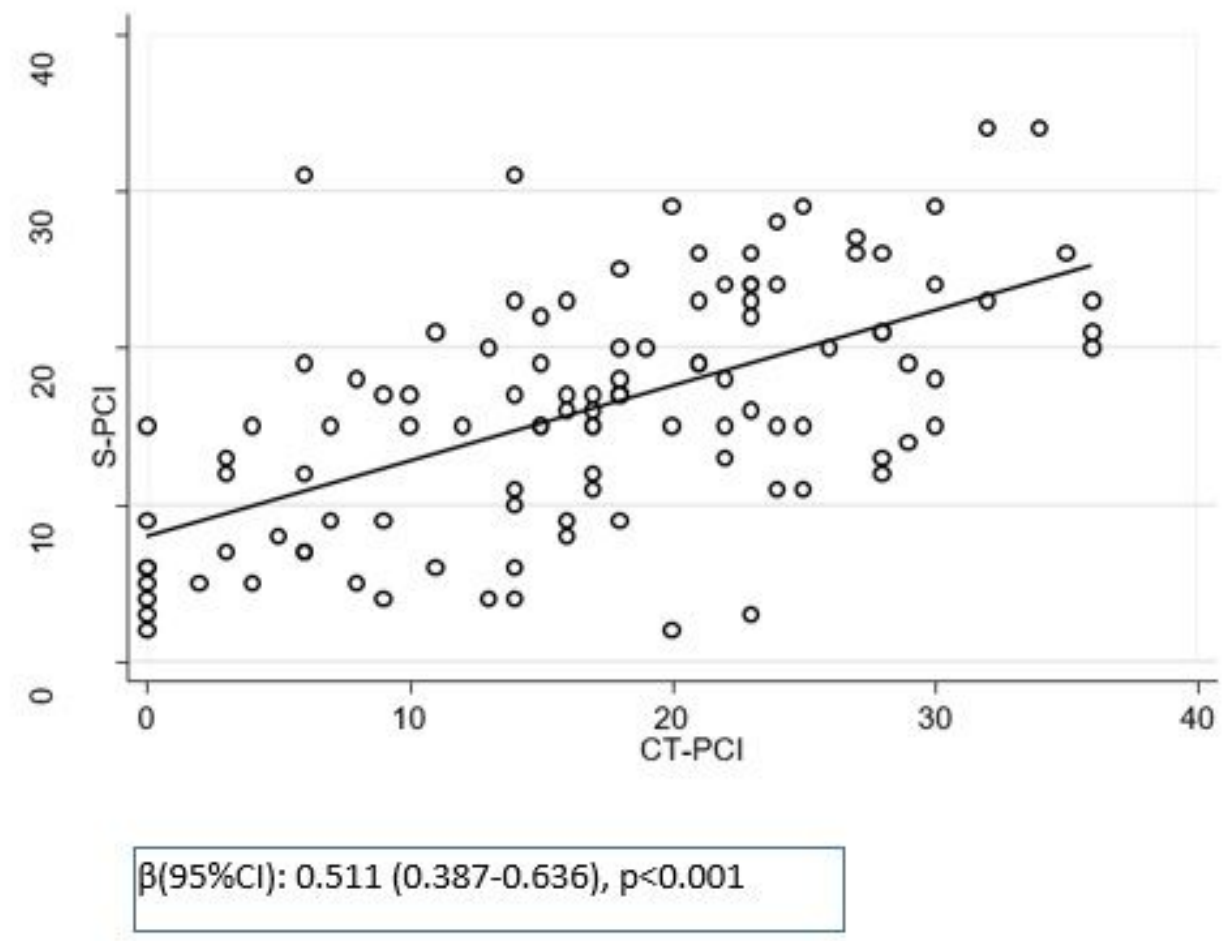

Figure 2

Linear regression analysis showing an association between increasing CT-PCl and S-PCI.

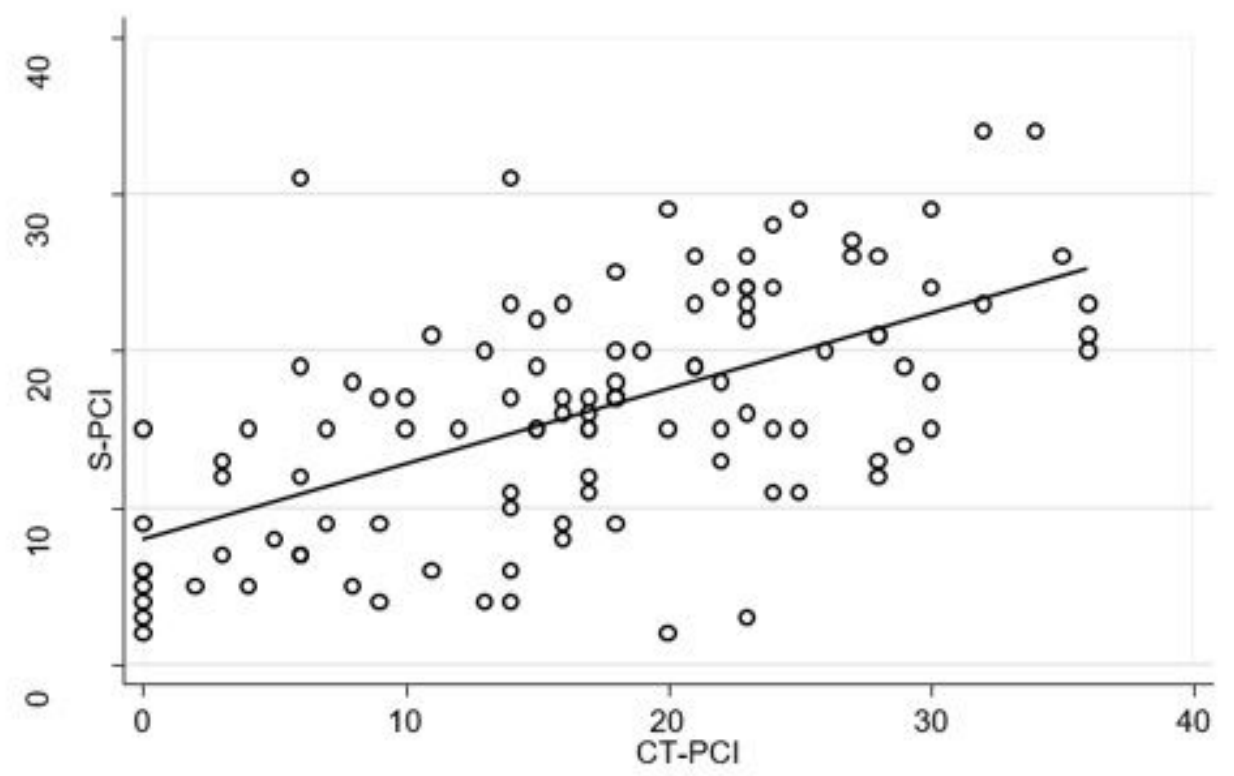

$\beta(95 \% \mathrm{Cl}): 0.511(0.387-0.636), p<0.001$

Figure 2 
Linear regression analysis showing an association between increasing CT-PCl and S-PCI. 